\title{
Disc degeneration after disc herniation: are we accelerating the process?
}

\author{
Authors Josh E Schroeder ${ }^{1}$, Joseph R Dettori ${ }^{2}$, Erika D Brodt ${ }^{2}$, Leon Kaplan ${ }^{1}$ \\ Institutions ${ }^{1}$ Orthopedic Department, Hadassah Hebrew University Medical Center Jerusalem, Israel \\ 2 Spectrum Research Inc, Tacoma, WA, USA
}

\section{ABSTRACT}

Study design: Systematic review.

Study rationale: Disc degeneration is a common process starting early in life. Often disc herniation is an early step in disc degeneration, which may cause pain or stenosis. How quickly this subsequent disc degeneration occurs following a disc herniation and subsequent surgical treatment and whether certain spinal procedures increase the rate of degeneration remain unclear.

Objectives: To investigate the risk of subsequent radiographic disc degeneration following discectomy, discography, and conservative care in patients with a first-time diagnosed herniated nucleus pulpous (HNP) and to ascertain whether this risk in these defined groups changes over time.

Methods: A systematic review of pertinent articles published up to June 2012. Key articles were searched to identify studies evaluating the risk of subsequent radiographic disc degeneration following treatment for HNP. Studies that included patients undergoing secondary surgery for disc herniation or that did not use a validated classification system to measure the severity of disc degeneration were excluded. Two independent reviewers assessed the strength of evidence using the GRADE criteria and disagreements were resolved by consensus.

Results: From a total of 147 possible citations, three cohort studies (class of evidence III) met our inclusion criteria and form the basis for this report. The risk of subsequent lumbar disc degeneration following standard discectomy was significantly greater compared with both microdiscectomy $(48.7 \%$ vs $9.1 \%)$ and asymptomatic controls (90\% vs $68 \%)$ in two studies with mean follow-ups of 5.5 and 25.3 years, respectively. Following conservative care for first-time HNP in the third study, the risk of progression of lumbar disc degeneration was $47.6 \%$ over the first 2 years of follow-up and $95.2 \%$ over the next 6 years of follow-up. In the same study, the risk of lumbar disc degeneration was shown to increase incrementally over the course of the 8-year follow-up, with all patients showing signs of degeneration at final examination.

Conclusion: Standard discectomy in first-time lumbar HNP may increase the risk of subsequent same-level lumbar disc degeneration compared with microdiscectomy as seen in one low-quality study. However, disc degeneration is likely a natural, temporal consequence following HNP, as demonstrated in a second low-quality study. The overall strength of evidence for the conclusions is very low. 


\section{STUDY RATIONALE AND CONTEXT}

Disc degeneration is a common process starting in the second decade of life $[1,2]$. We commonly use imaging tests to quantify its severity [3]. In many cases, disc herniation is an early step in disc degeneration [4]. As the disc progressively degenerates, it may clinically manifest itself with pain or stenosis. How quickly this subsequent disc degeneration occurs following treatment for disc herniation and whether certain spinal procedures increase the rate of degeneration remain unclear. Of particular concern is if nonoperative care may be associated with a slower rate of progression than invasive diagnostic or surgical interventions, and if certain less invasive procedures offer advantages over more conventional extensile procedures.

\section{OBJECTIVES}

To investigate the risk of subsequent radiographic disc degeneration following discectomy, discography, or conservative care in patients with a first-time diagnosed herniated nucleus pulpous (HNP) and to ascertain whether this risk in these defined groups changes over time.

Fig 1 Results of literature search.
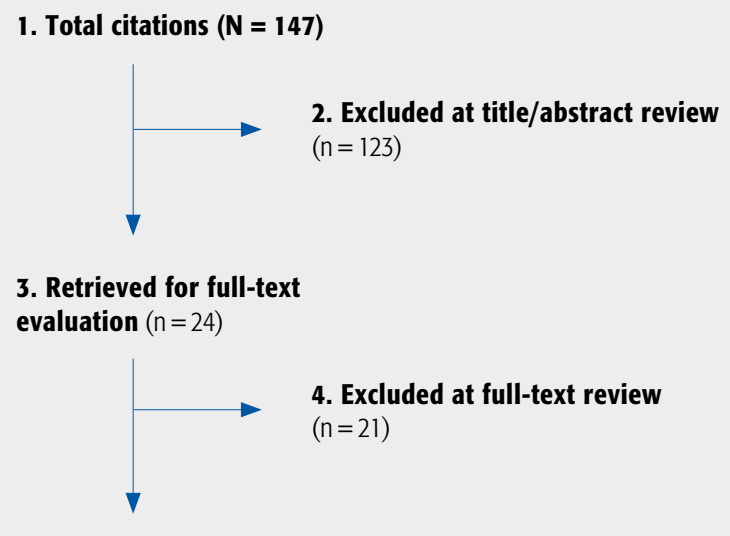

5. Publications $(n=3)$

\section{MATERIALS AND METHODS}

Study design: Systematic review.

Search: PubMed; Cochrane collaboration database; National Guideline Clearinghouse database; bibliographies of key articles.

Dates searched: 1970 through June 4, 2012.

Inclusion criteria: (1) adults, (2) discectomy, discography or conservative treatment for first-time HNP.

Exclusion criteria: (1) secondary surgery for HNP, (2) fusion surgery, (3) tumor, (4) infection, (5) no disc severity classification system to measure disc degeneration, and (6) clinical outcomes only reported.

Outcomes: Severity classification system of disc degeneration (Kambin severity scale or Pfirrmann classification).

Analysis: Descriptive statistics of the cumulative incidence or prevalence.

Cumulative incidence: The proportion of people who had been degeneration-free at the time of the initial evaluation that had subsequent development of new degeneration at final follow-up.

Prevalence: The proportion of people with disc degeneration at any follow-up point.

Data were summarized in tables and figures but were not pooled due to the limited number of studies available and the heterogeneity of patient populations, outcome measures, and follow-up periods.

Overall strength of evidence: Risk of bias determined using CoE rating scheme developed by the Oxford Centre for Evidence-based Medicine by The Journal of Bone and Joint Surgery American Volume [Wright] (see Web Appendix at www.aospine.org/ebsj). The overall body of evidence with respect to each key question was determined based on modified precepts outlined by the Grades of Recommendation Assessment, Development and Evaluation (GRADE) system. 


\section{RESULTS}

- From 147 citations, 24 articles underwent full-text review; three cohort studies, all graded CoE III, met our inclusion criteria and form the basis for this report (Fig 1). Characteristics of each study are outlined in Table 1. See Web Appendix at www.aospine.org/ebsj for critical appraisal and a list of excluded articles.

- We found no studies reporting the risk of radiographic disc degeneration following discography for HNP.

- Two studies investigated the risk of disc degeneration following standard discectomy; one compared with posterolateral microdiscectomy [5] and one compared with asymptomatic controls [6]. The third study was conducted in patients who had undergone conservative care [7].

\section{Key question 1: What is the risk of subsequent radiographic disc degeneration following discectomy, discography, and conservative care in patients with a first-time diagnosed HNP?}

\section{Standard discectomy vs posterolateral microdiscectomy (Fig 2, Table 2)}

- The discectomy $(n=39)$ and microdiscectomy $(n=44)$ groups differed regarding gender (males: $69.2 \%$ vs $39.5 \%)$ and percentage follow-up $(78.0 \%$ vs $88.0 \%)$, respectively.

- Patients who underwent standard discectomy showed a fivefold greater cumulative incidence of moderate to severe (grade $\geq 2$, Kambin severity scale) lumbar disc degeneration at a mean of 5.5 years' follow-up than those who underwent microdiscectomy: $48.7 \%$ vs $9.1 \%$ (relative risk $[\mathrm{RR}]=5.4 ; 95 \%$ confidence interval [CI], 2.0-14.4; $P=.0001$ ).

- In the standard discectomy group, only $20.5 \%$ of patients showed no signs of subsequent disc degeneration (grade 0) whereas in the microdiscectomy group, most patients $(61.4 \%)$ showed no subsequent degeneration.

\section{Standard discectomy vs asymptomatic controls (Fig 3, Table 2)}

- The two groups ( $\mathrm{n}=50$ each) were matched for age and gender with most patients being men $(66.0 \%)$ with a mean age of 64 years.

- The prevalence of moderate to severe (grade $\geq 2$, Kambin severity scale) lumbar disc degeneration at a mean follow-up of 25.3 years was significantly greater in the discectomy group $(90 \%)$ compared with the asymptomatic control group (68\%) $(\mathrm{RR}=1.3 ; 95 \% \mathrm{CI}$, $1.1-1.6 ; P=.012)$.

\section{Conservative treatment}

- Of 21 patients treated conservatively, $38.1 \%$ were men with a mean age of 49 years.

- The prevalence of progression of disc degeneration, defined as an increase of $1-2$ grades, was $47.6 \%$ from initial presentation to 2 years, and $95.2 \%$ from 2 years to final follow-up. When defined as an increase of two grades, the prevalence of progression was $4.8 \%$ and $47.6 \%$, respectively.
Fig 2 Cumulative incidence of lumbar disc degeneration (Kambin severity scale) at a mean follow-up of 5.5 years following standard discectomy and microdiscectomy.

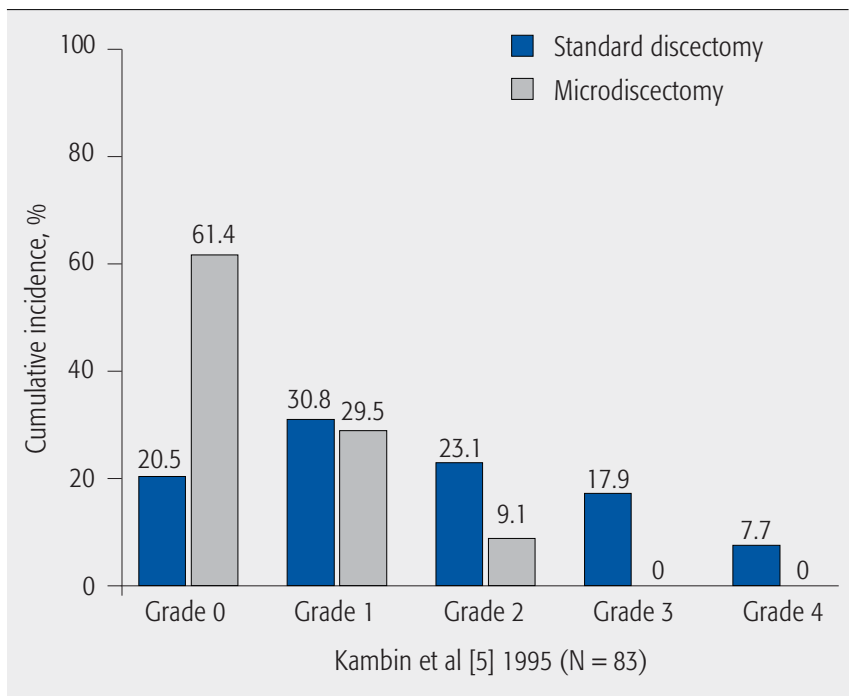

Fig 3 Prevalence of moderate to severe lumbar disc degeneration (grade $\geq 2$ on the Kambin severity scale) at a mean follow-up of 25.3 years following standard discectomy and among asymptomatic controls.

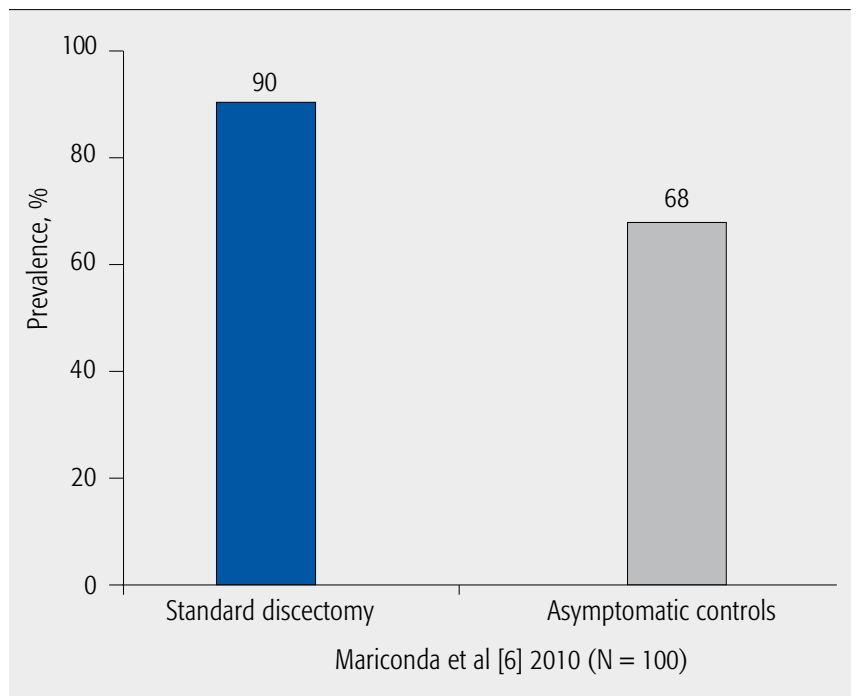


Table 1 Included studies for risk of radiographic disc degeneration following herniated nucleus pulpous in the lumbar spine.

\begin{tabular}{|c|c|c|c|c|c|}
\hline Author (y) & $\begin{array}{l}\text { Study } \\
\text { design }\end{array}$ & Treatment & Population & $\begin{array}{l}\text { Follow-up } \\
\text { (\% followed up) }\end{array}$ & $\begin{array}{l}\text { Definition of radiographic spinal } \\
\text { degeneration }\end{array}$ \\
\hline $\begin{array}{l}\text { Kambin et al [5] } \\
\text { (1995) }\end{array}$ & Cohort & $\begin{array}{l}\text { Posterior laminotomy } \\
\text { and discectomy } \\
\text { (group 1) } \\
\text { Posterolateral } \\
\text { microdiscectomy } \\
\text { (group 2) }\end{array}$ & $\begin{array}{l}\text { Group } 1 \\
-N=39 \\
\text { - Male: } 69.2 \% \\
\text { - Mean age: } 40.3 \pm 2.0 y \\
\text { Group } 2 \\
-N=44 \\
\text { - Male: } 39.5 \% \\
\text { - Mean age: } 41.9 \pm 1.8 y\end{array}$ & $\begin{array}{l}\text { Group 1: mean } 5.4 \text { y } \\
(78 \% ; 39 / 50) \\
\text { Group 2: mean } 5.6 \text { y } \\
(88 \% ; 44 / 50) \\
83 \%(83 / 100)\end{array}$ & $\begin{array}{l}\text { Kambin severity scale (radiograph): } \\
\text { Grade 0: } \\
\text { absence of degenerative changes } \\
\text { Grade 1: } \\
\text { marginal osteophytes, absence of disc space narrowing and } \\
\text { normal facet joints } \\
\text { Grade 2: } \\
\text { narrowing of the intervertebral disc space } \leq 33 \% \text { associated } \\
\text { with marginal osteophytes } \\
\text { Grade 3: } \\
\text { narrowing of the intervertebral disc space }>33 \% \text { in the } \\
\text { presence of large marginal osteophytosis and hypertrophic } \\
\text { changes of facet joints } \\
\text { Grade 4: } \\
\text { complete collapse of the disc space and/or the } \\
\text { development of degenerative spondylolisthesis }\end{array}$ \\
\hline $\begin{array}{l}\text { Mariconda et al } \\
\text { [6] (2010) }\end{array}$ & Cohort & $\begin{array}{l}\text { Standard discectomy } \\
\text { (group 1) } \\
\text { Matched, } \\
\text { asymptomatic } \\
\text { nonoperated } \\
\text { subjects (group 2) }\end{array}$ & $\begin{array}{l}\text { Group } 1 \\
\text { - N=50 } \\
\text { - Male: } 66.0 \% \\
\text { - Mean age: } 63.4 \pm 8.4 y \\
\text { Group } 2 \\
-N=50 \\
\text { - Male: } 66.0 \% \\
\text { - Mean age: } 64.7 \pm 9.6 y\end{array}$ & $\begin{array}{l}\text { Mean } 25.3 \pm 3.0 y \\
\% \text { Not reported }\end{array}$ & Kambin severity scale (radiograph) \\
\hline $\begin{array}{l}\text { Masui et al [7] } \\
(2005)\end{array}$ & Cohort & $\begin{array}{l}\text { Conservative } \\
\text { treatment }\end{array}$ & $\begin{array}{l}\mathrm{N}=21 \\
\text { Male: } 38.1 \% \\
\text { Mean age: } 49 \\
\text { (range, 24-68) y }\end{array}$ & $\begin{array}{l}\text { Mean } 8.1 \\
\text { (range, } 7.3-10.0) \text { y } \\
52.5 \%(21 / 40)\end{array}$ & $\begin{array}{l}\text { Pfirrmann classification (MRI): } \\
\text { Grade I } \\
\text { - Structure: homogeneous, bright white } \\
\text { - Distinction of nucleus and anulus: clear } \\
\text { - Signal intensity: hyperintense, isointense to cerebrospinal } \\
\text { fluid } \\
\text { - Disc height: normal } \\
\text { Grade II } \\
\text { - Structure: inhomogeneous with or without horizontal } \\
\text { bands } \\
\text { - Distinction of nucleus and anulus: clear } \\
\text { - Signal intensity: hyperintense, isointense to cerebrospinal } \\
\text { fluid } \\
\text { - Disc height: normal } \\
\text { Grade III } \\
\text { - Structure: inhomogeneous, gray } \\
\text { - Distinction of nucleus and anulus: unclear } \\
\text { - Signal intensity: intermediate } \\
\text { - Disc height: normal to slightly decreased } \\
\text { Grade IV } \\
\text { - Structure: in homogeneous, gray to black } \\
\text { - Distinction of nucleus and anulus: lost } \\
\text { - Signal intensity: intermediate to hypointense } \\
\text { - Disc height: normal to moderately decreased } \\
\text { Grade V } \\
\text { - Structure: inhomogeneous, black } \\
\text { - Distinction of nucleus and anulus: lost } \\
\text { - Signal intensity: hypointense } \\
\text { - Disc height: collapsed disc space }\end{array}$ \\
\hline
\end{tabular}


Key question 2: Does this risk of subsequent radiographic disc degeneration in these defined groups change over time?

\section{Conservative treatment (Fig 4, Table 2)}

- The prevalence of moderate to severe (grade $\geq$ III, Pfirrmann classification) lumbar disc degeneration increased incrementally over the study period from $28.6 \%$ at initial presentation to $66.6 \%$ at 2 years, and finally to $100 \%$ at the 8 -year follow-up.

\section{CLINICAL GUIDELINES}

No clinical guidelines were found addressing this topic.

Fig 4 Prevalence of moderate to severe lumbar disc degeneration (grade $\geq$ III using the Pfirrmann classification) at initial presentation, 2 years, and 8 years following conservative treatment.

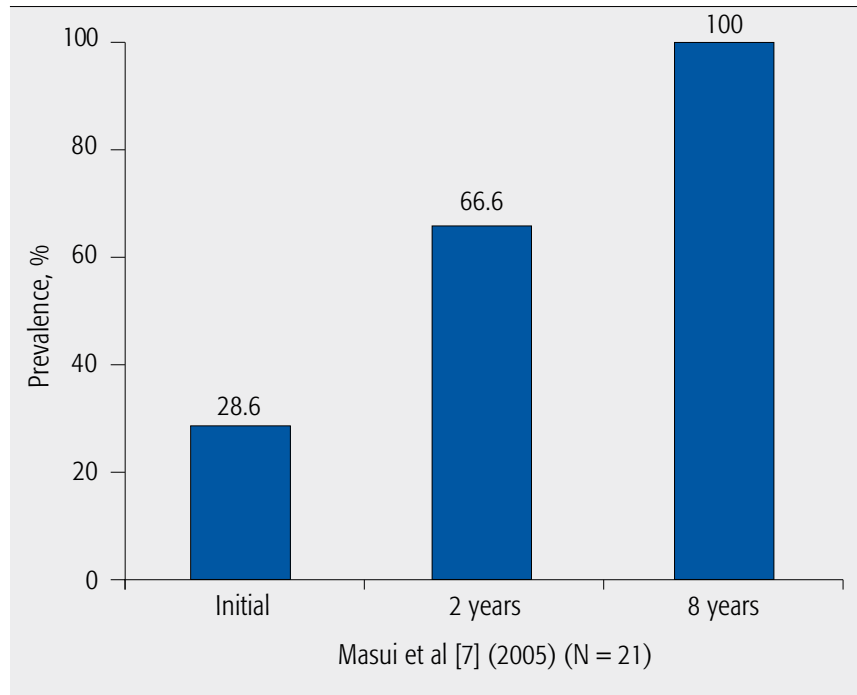

Table 2 Summary of reported risks of subsequent disc degeneration following various treatments for lumbar herniated nucleus pulpous.

\begin{tabular}{|c|c|c|c|c|c|c|c|c|c|}
\hline \multirow[t]{2}{*}{ Author (y) } & \multirow[t]{2}{*}{ Outcome } & \multirow{2}{*}{$\begin{array}{l}\text { Definition of } \\
\text { degeneration }\end{array}$} & \multirow[t]{2}{*}{ Population } & \multicolumn{5}{|c|}{ Grade, \% } & \multirow{2}{*}{$\begin{array}{l}\text { Follow-up, } \\
\text { mean }\end{array}$} \\
\hline & & & & $\mathbf{0}$ & 1 & 2 & 3 & 4 & \\
\hline \multirow[t]{2}{*}{ Kambin et al [5] (1995) } & Cumulative incidence & Kambin severity scale & Standard discectomy & 20.5 & 30.8 & 23.1 & 17.9 & 7.7 & $5.5 y$ \\
\hline & & & Microdiscectomy & 61.4 & 29.5 & 9.1 & 0 & 0 & \\
\hline \multirow[t]{3}{*}{ Mariconda et al [6] (2010) } & Prevalence & Kambin severity scale & Standard discectomy & 4.0 & 6.0 & 26.0 & 58.0 & 6.0 & $25.3 y$ \\
\hline & & & Controls & 10.0 & 22.0 & 26.0 & 26.0 & 16.0 & \\
\hline & & & & $\mathbf{I}$ & II & III & IV & $\mathbf{v}$ & \\
\hline \multirow[t]{3}{*}{ Masui et al [7] (2005) } & Prevalence & Pfirrmann classification & Conservative care & 9.5 & 61.9 & 23.8 & 4.8 & 0 & Initial \\
\hline & & & & 0 & 33.3 & 57.1 & 9.5 & 0 & $2 y$ \\
\hline & & & & 0 & 0 & 9.5 & 61.9 & 28.6 & 8.1 y \\
\hline
\end{tabular}


Table 3 Strength of evidence summary.

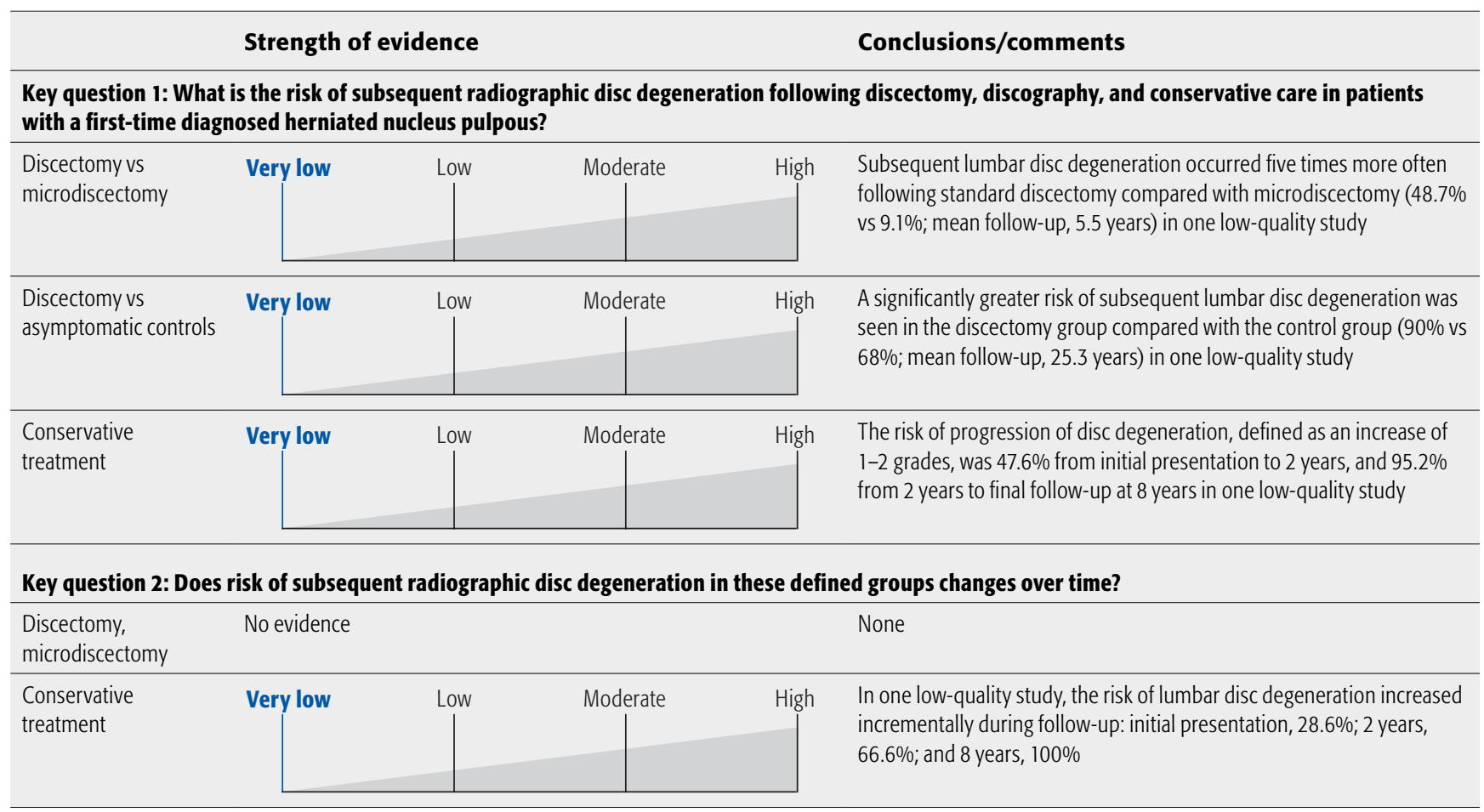

\section{EVIDENCE SUMMARY}

The overall strength of evidence evaluating the risk of subsequent radiographic degeneration in the lumbar spine following standard discectomy compared with microdiscectomy, standard discectomy compared with asymptomatic controls, and conservative treatment for first-time HNP is very low, that is, any effect estimate is uncertain (Table $\mathbf{3}$ ). The overall strength of evidence evaluating whether this risk of subsequent radiographic disc degeneration changes over time is also very low, as addressed by only one study in patients undergoing conservative care.

\section{ILLUSTRATIVE CASE}

A 53-year-old healthy woman suffered from extreme radicular pain in her right leg in the S1 distribution. On magnetic resonance imaging (MRI), a central disc herniation was noted (Fig 5). She was treated with oral analgesics and physical therapy; however, the pain did not remit. Six months later she was referred for a discectomy. On surgery, a standard discectomy was performed and a large disc fragment was removed from the canal (Fig 6). Her pain resolved and she went back to her daily life. Nine months later, she returned to the clinic with a new onset of lower back pain and pain radiating down the left leg. A new MRI was performed showing loss of disc height, severe degeneration, and recurrent herniation of the disc (Fig 7). 
Fig 5 Preoperative sagittal and axial magnetic resonance images of the spine. A L5-S1 central disc herniation is noted.

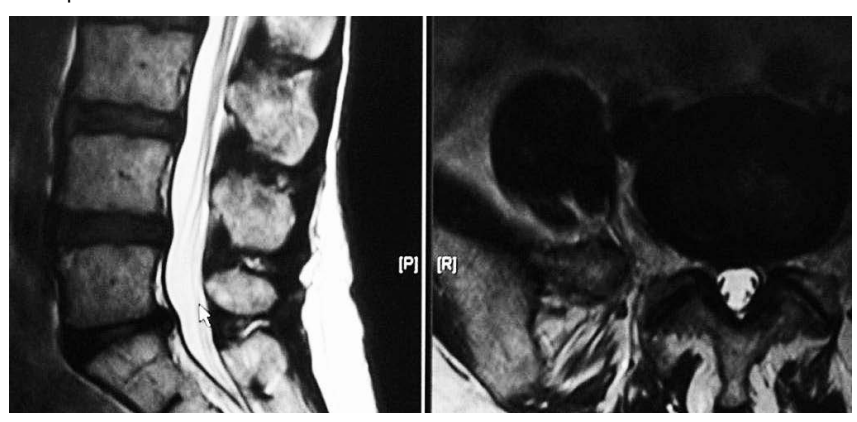

Fig 6 Intraoperative image of the disc tissue removed in surgery.

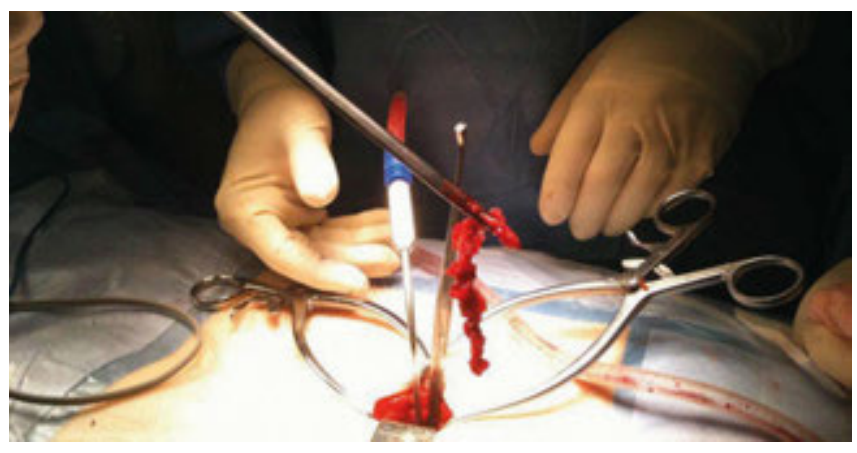

Fig 7 Sagittal magnetic resonance image taken 9 months postoperatively showing advancement to severe disc degeneration with positive Modic end plate changes and reherniation of the L5-S1 disc.

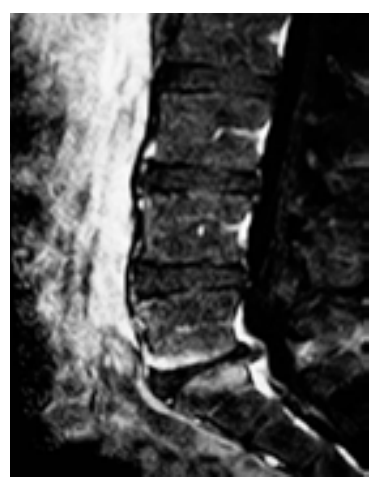

\section{DISCUSSION}

\section{- Strengths:}

- We included only studies that used a severity classification system to measure disc degeneration.

\section{- Limitations:}

- Few studies were available to address the issue, all with small sample sizes $(n=83, n=100, n=21)$.

- All studies were class of evidence III.

- Heterogeneity of patient populations, outcome measures, and follow-up periods made comparisons across studies difficult.

- No studies were found that met our criteria in patients treated with discography.

- Not all cases of HNP will lead to advanced disc degeneration in 5 to 10 years; however, close to two-thirds will show some signs of degeneration.

- Surgical intervention may increase the risk of disc degeneration.

- Standard discectomy may cause more degeneration than microdiscectomy.

- The biologics behind disc nutrition and degeneration and the effects of interventions on these processes need to be better understood.

- As discectomy is the most common spine procedure in the world, better data needs to be gathered on the long-term effects of surgical procedures. 


\section{REFERENCES}

1. Boos N, Weissbach S, Rohrbach $H$, et al (2002) Classification of age-related changes in lumbar intervertebral discs: 2002 Volvo Award in basic science. Spine; 27(23):2631-2644.

2. Haefeli M, Kalberer F, Saegesser D, et al (2006) The course of macroscopic degeneration in the human lumbar intervertebral disc. Spine; 31(14):1522-1531.

3. Modic MT, Masaryk TJ, Ross JS, et al (1988) Imaging of degenerative disk disease. Radiology; 168(1):177-186.

4. Naylor A (1962) The biophysical and biochemical aspects of intervertebral disc herniation and degeneration. Ann R Coll Surg Engl; 31:91-114.

5. Kambin P, Cohen LF, Brooks M, et al (1995) Development of degenerative spondylosis of the lumbar spine after partial discectomy: comparison of laminotomy, discectomy, and posterolateral discectomy. Spine; 20(5):599607.

6. Mariconda $M$, Galasso 0 , Attingenti $\mathbf{P}$, et al (2010) Frequency and clinical meaning of long-term degenerative changes after lumbar discectomy visualized on imaging tests. Eur Spine J; 19(1):136-143.

7. Masui T, Yukawa Y, Nakamura S, et al (2005) Natural history of patients with lumbar disc herniation observed by magnetic resonance imaging for minimum 7 years. J Spinal Disord Tech; 18(2):121-126.

\section{EDITORIAL PERSPECTIVE}

The reviewers were positive about the idea for and the execution of this systematic review, noting that this seemingly important question had received surprisingly scant attention in the peerreviewed literature to date.

Again, this is less of a question for Schroeder and colleagues and more of an issue for the original authors of the pertinent studies. The question remains, whether a 'sequestrectomy' or 'fragmentectomy' (removing only the offending fragment) is different from a 'formal discectomy,' in which the intervertebral segment is entered with instruments and further loose nucleus and annular materials are removed, or if the choice of magnification system (operating microscope vs surgeon loupes) has an effect on the rate and severity of disc degeneration. The data presented seems to imply that 'less is more' from a disc degeneration perspective as long as the offending disc fragment is removed; clearly, aggressive intervertebral maneuvers such as end-plate curettage seem not supported by these studies.

In the big picture, this systematic review clearly outlines the inexorable progression of lumbar disc degeneration over time - with a stated $68 \%$ incidence over 25 years in asymptomatic controls. Sadly, it seems clear that disc herniation is a common, first major step into the degenerative vortex of disc degeneration.

The increasing availability of large-scale digital imaging repositories will, in the future, hopefully allow for more longitudinal assessment of the variables that surround disc degeneration. 